\title{
Environmental Protection and Economic Growth
}

\section{Proteção Ambiental e Crescimento Econômico}

\author{
Vladimir Kuhl Teles* \\ Ronaldo Arraes**
}

\begin{abstract}
This paper explores the link between environmental policy and economic growth by employing an extension of the AK Growth Model, in which is included a state equation for renewable natural resources. We assume that the change in environmental regulations induces costs and that economic agents also derive some utility from capital stock accumulation vis-à-vis the environment. Based upon the Hopf bifurcation theorem, we show that cyclical environmental policy strategies are optimal, providing theoretical support for the Environmental Kuznets Curve.
\end{abstract}

Keywords: AK growth model. Environmental Kuznets curve. Hopf bifurcation theorem. Limit cycles.

Resumo: Este artigo explora a conexão entre política ambiental e crescimento econômico empregando uma extensão do modelo de crescimento AK, no qual está incluída uma equação de estado para recursos naturais renováveis. Assume-se que mudanças nas regulações ambientais induzem custos e que os agentes econômicos também obtêm alguma utilidade da acumulação de estoque de capital vis-à-vis o meio ambiente. Com base no teorema de bifurcação de Hopf, mostra-se que as estratégias de política ambiental cíclica são ótimas, fornecendo suporte teórico para a curva ambiental de Kuznets.

Palavras-chave: Modelo de crescimento AK. Curva ambiental de Kuznets. Teorema de bifurcação de Hopf. Ciclos limites.

JEL Classification: C61; C62; D62.

\section{Introdução}

The empirical evidence of Grossman and Krueger (1995, 1996), which suggests a relationship between per capita GNP and the emission of pollutants in the form of an inverted $U$, has generated great interest regarding the relationship between economic growth and environmental protection. This inverted $U$ has been dubbed the environmental Kuznets curve (EKC). The issue raised by such a stylized fact is: does economic growth in itself ensure the automatic protection of the environment?

The above question has been answered positively by those who argue that a growth policy is always the best course of action. In this sense, Jorgenson and Wil-

\footnotetext{
* Doutor em Economia pela Universidade de Brasília. Professora da Escola de Economia de São Paulo da Fundação Getúlio Vargas (EESP-FGV).E-mail: vladimir.teles@fgv.br

* $\quad$ Doutor em Economia Agrícola pela University of Georgia, USA. Professor da Universidade Federal do Ceará. E-mail: ronald@ufc.br
} 
coxen (1990) have provided estimates for environmental regulation fees associated with the accumulation of capital and growth. They then verified that, during the 1974-1985 period, these costs reduced average annual growth in the U.S. by 0.2 percentage points. These results corroborate those obtained by Hazilla and Kopp (1990). At the same time, Schmalensee (1993) and Jaffe et al. (1995) have also suggested that these costs have been underestimated, since environmental regulation costs can have negative effect son production rates, investment, and productivity.

The above assertions have been refuted by several studies (e.g. EL SERAFY; GOODLAND [1996], and CLARK [1996]) that argue economic growth behaves indiscriminately with regard to environmental protection. The authors of these studies have insisted on the need for direct governmental intervention by taxing the use of natural resources in order to protect the environment. In support of this hypothesis, Margulis (1992) uses data from Mexico to show empirically that pollution causes serious damage to labor productivity, while Pearce and Warford (1993) have produced a detailed accounting of productivity losses from pollution in many countries.

In this paper, we investigate the EKC using an AK growth model. Some papers have included pollution in various AK models ${ }^{1}$ (e.g. MICHEL; ROTILLON, 1995; MOHTADI, 1996; SMULDERS; GRADUS, 1996; XEPAPADEAS, 1997, RUBIO; AZNAR, 2000; REIS, 2001; CHEVÉ, 2002), but here we include government environmental regulation and the costs associated with changing that regulation. Our extensions offer a greater likelihood of understanding the empirical facts, and in particular the pollution-income relationship that underlies the EKC. In other words, we develop an AK model that predicts relevant EKC behavior.

Many papers have described the reasons for EKC using growth models (e.g. JOHN; PECCHENINO, 1994; SELDEN; SONG, 1995; STOKEY, 1996; BELTRATTI, 1996; JAEGER, 1998; JONES; MANUELLI, 2001; ANDREONI; LEVINSON, 2001; LEVINSON, 2002). Our model, however, yields very different predictions. While most of the existing models corroborate the idea that economic growth itself ensures the automatic protection of the environment, we identify a very long-term cycle between environment and income that mirrors an EKC initially, but follows an explosively different path thereafter.

We note from this discussion that the environmental Kuznets curve is frequently used to suggest that there is no need to tax the use of natural resources, since the growth process itself should automatically generate environmental protection. Therefore, the aim of this study is to suggest an alternative interpretation for the Kuznets curve by formalizing a growth model in which the source of the relation between growth and the environment in the inverted $\mathrm{U}$ format is given

$1 \quad$ A complete and extensive survey on growth models with environment can be found in Xepapadeas (2005). 
by the environmental regulation system itself. Under this framework, the environmental Kuznets curve is obtained from the cyclical relation that exists between environmental regulation and the long-run accumulation of capital resulting from the existence of regulatory policy adjustment costs and the insertion of a utility gain hypothesis in capital stock accumulation vis-à-vis the environment.

In this context, we seek to make the model more realistic by relaxing the hypothesis according to which variables such as the accumulation of capital and institutional environmental protection norms adjust themselves instantaneously over time. Relaxing this hypothesis abandons the theoretical simplification that makes the traditional model analytically convenient, and also offers a reasonable explanation for the environmental Kuznets curve.

The analysis developed here is divided into two parts. The first part is comprised of an extension of the $\mathrm{AK}$ model that takes into account the environment and the regulating agent. In this regard, the relation between capital stock and the environment remains linear over time. The second part of the analysis involves the insertion of regulatory policy adjustment costs, which results in a cyclical relation between growth and the environment, thus leading to behavior similar to the empirical findings regarding the environmental Kuznets curve.

\section{Incorporating the Environment into the AK Growth Model}

The first model includes the state equation for the environment within the AK model, and assumes an overall formulation of environmental dynamics that is given by:

$$
\dot{E}=\beta R+\phi E-\varphi K
$$

where $\dot{E}$ is the variation rate of the natural resource stock, $\mathrm{R}$ is regulation rateimposed on the productive sector for degradation of natural resources over time $t$ (or the environmental "reconstruction" rate imposed on the productive sector), $\beta$ is theparameter that indicates the marginal recomposition of the environment with regard to the environmental regulation rate, $\mathrm{E}$ is the environmental stock over time $\mathrm{t}, \phi$ is the natural recomposition rate of the environment, $\mathrm{K}$ is the capital stock at time $t$, and $\varphi$ is the marginal destruction rate of the environment related to the use of the capital stock.

The capital stock variation rate is given by:

$$
\dot{K}=A K-C-R-\delta K
$$


where $\dot{K}$ is the physical capital stock variation, A is the productivity of the economy's various factors (where production is an AK function), $\mathrm{C}$ is consumption overtime $\mathrm{t}$, and $\delta$ is the depreciation rate. All the variables are expressed in per capitaterms.

At the same time, defining the following relations,

$$
\begin{aligned}
& \mathrm{k}=(\mathrm{K} / \mathrm{E}) \\
& \mathrm{c}=(\mathrm{CE})
\end{aligned}
$$

and

$$
\mathrm{r}=(\mathrm{RE})
$$

Equations 1 and 2 may be synthesized as follows:

$$
\dot{k}=k[A-\delta-\beta r-\phi+\varphi k]-c-r
$$

Lastly, considering that the utility of the agents depends on the relationships between consumption and the environment, and between the rate of regulation and the environment, we derive the following intertemporal optimization problem for the social planner:

$$
\begin{array}{r}
\max \int_{0}^{\infty} e^{-\rho t} u(c, r) d t \\
\text { s.t } \dot{k}=k[A-\delta-\beta r-\phi+\varphi k]-c-r
\end{array}
$$

where $\rho>0$ is the temporal discount rate. This equation is a simple dynamics optimization model with two control variables, $\mathrm{r}$ and $\mathrm{c}$, and a state variable, $\mathrm{k}$.

The current Hamiltonian value is given by,

$$
\mathrm{H}=\mathrm{u}(\mathrm{c}, \mathrm{r})+\lambda\{\mathrm{k}[\mathrm{A}-\delta-\beta \mathrm{r}-\phi+\varphi \mathrm{k}]-\mathrm{c}-\mathrm{r}\}
$$

where $\lambda$ is the co-state variable. The first order conditions are:

$$
\begin{gathered}
\mathrm{u}_{\mathrm{r}}=\lambda(\beta \mathrm{k}+1) \\
\mathrm{u}_{\mathrm{c}}=\lambda
\end{gathered}
$$


and

$$
\dot{\lambda}=\rho \lambda-\lambda[A-\delta-\beta r-\phi+2 \varphi k]
$$

Differentiating 9 with respect to time, we have:

$$
\frac{\dot{\lambda}}{\lambda}=\eta \frac{\dot{r}}{r}-\frac{\dot{k}}{k} \frac{\beta k}{(\beta k+1)}
$$

where $\eta=r \frac{u_{r r}}{u_{r}}$ is the elasticity of the marginal utility with respect to the regulation rate - environment ratio, which we assume to be constant. Thus, equating (12) and (11), and using (6), we arrive at:

$$
\frac{\dot{r}}{r}=\frac{\rho-\frac{1}{\beta k+1}(A-\delta-\phi+\varphi k+\beta c)-\varphi k}{\eta}
$$

at the same time, rewriting 6 we have:

$$
\frac{\dot{k}}{k}=[A-\delta-\beta r-\phi+\varphi k]-\frac{c}{k}-\frac{r}{k}
$$

Thus, equations 13 and 14 describe the optimal trajectory of $r$ and $k$. These trajectories are illustrated in Figure 1 in Appendix A. The $(\dot{r} / \mathrm{r})=0$ function is vertical in space k-r, since:

$$
\left(\frac{d r}{d k}\right)_{\frac{\dot{r}}{r}}=0
$$

At the same time, the shape of the $(\dot{k} / \mathrm{k})$ function in space $\mathrm{k}-\mathrm{r}$ is given by:

$$
\left(\frac{d r}{d k}\right)_{\frac{k}{k}}=\frac{A-\delta-\phi+2 \varphi k+\beta\left(c+\varphi k^{2}\right)}{(1+\beta k)^{2}}
$$

This will be positive if the natural recomposition of the environment, $\phi$, and thecapital depreciation are small enough. This is an expected result given that the optimal environmental regulation tax will increase with the value of capital stock only if the natural environment cannot repair itself.

The phase diagram that illustrates the dynamics of the economy is presented in Figure 1. In that sense, if $\mathrm{k}>\mathrm{k}^{*}$, the optimal path is obtained through an increase 
in $\mathrm{r}$, and if $\mathrm{k}<\mathrm{k}^{*}, \mathrm{r}$ must decline in order to achieve the optimal dynamics. Accordingly, tax regulation should be used in order to maintain $\mathrm{k}$ at the constant $\mathrm{k}^{*}$ level. At sametime, if $\mathrm{r}$ is above the $k / \mathrm{k}=0$ isocline, given a value of $\mathrm{k}$, the capital stock will fall. And if $r$ is below the isocline, $\mathrm{k}$ will increase.

The phase diagram in Figure 1 implies an unstable solution path in a counter clockwise spiral. So, when $\mathrm{k}$ is growing, $\mathrm{r}$ is falling and the environment is being depleted. But, afterwards, $\mathrm{r}$ may begin to rise and the growth in $\mathrm{k}$ falls. This trajectory is similar tothat depicted in the EKC.

The basic conclusion of this section is that the EKC may be a spiral solution to a maximizing social planner problem.

\section{Adjustment Costs of Regulation and the Environmental Kuznets Curve}

Although the analysis outlined in section 2 provides us with important hypotheses for our analysis, we can also develop the model by incorporating adjustment costs for environmental regulation policies in order to analyze the consequences on the environmental Kuznets curve's dynamics. This is an important advance once we better describe the choice of regulation policies given an optimal path. Also, as is made clear by the evidence presented in Grossman and Krueger (1995), it is probable that those countries that have reached the "end" of the environmental Kuznets curve will once again manifest environmental misuse trends as per capita income increases. In other words, the relation between the environment and growth seems to display cyclical behavior in the long run.

In an attempt to provide an explanation for these facts, we suggest that there are adjustment costs in terms of both capital stocks and environmental regulation policies. In this context, relaxing the hypothesis stating that variables like the accumulation of capital and institutional environmental protection rules are instantaneously adjusted over time makes the model more realistic. It accomplishes this by abandoning a certain theoretical simplification in order to make the traditional model more analytically convenient. Thus, the insertion of a cyclical relation between the accumulation of capital and the environment is obtained by applying the Hopf Bifurcation Theorem, following the methodology proposed by Feichtinger, Novak and Wirl (1994).

Therefore, we consider that the utility function of the social planner is given by $\mathrm{u}(\mathrm{c}, \mathrm{r})+\mathrm{v}(\mathrm{k})-\mathrm{z}(\Phi)$, where $\mathrm{u}(\mathrm{c}, \mathrm{r})$ is the function that determines how the utilityvaries in relation to consumption and environmental regulation. The main part of thesocial planner's utility function, which is the basis for the explanation of non-linearityin the relationship between growth and the environment, is the second part, where the non-linearities are included. The function $\mathrm{z}(\Phi)$ symbolizes the social planner's disutility and the changes in environmental regulations. There are plenty of reasons 
to believe that there is some rigidity in environmental regulations and that it is difficult to implement environmental tax reforms that are associated with political and economic costs (SMULDERS, 2004). In addition, and as explained by Wirl (1999, p. 23), "it is obvious that scrubbers, filters, catalytic converters and other abatement devices are costly investments that take time. These costs account for the fact that the reduction of pollution, waste disposal, etc. is costly and sluggish". Therefore, we account for the assumption that there are costs in implementing environmental regulations. At the same time, the function $v(\mathrm{k})$ seeks to include capital externalities in the problem, following Feichtinger, Novak and Wirl (1994).

By inserting adjustment costs for environmental regulation policies into section 2, problem (7) then becomes:

$$
\begin{gathered}
\max \int_{0}^{\infty} e^{-\rho t}[u(c, r)+v(k)-z(\Phi)] d t \\
\text { s.t } \dot{k}=k[A-\delta-\beta r-\phi+\varphi k]-c-r \\
\dot{r}=\Phi \\
\lim _{t \rightarrow \infty} e^{-\rho t} \lambda_{k} k=0 \quad \lim _{t \rightarrow \infty} e^{-\rho t} \lambda_{r} r=0
\end{gathered}
$$

This way, the current Hamiltonian value for problem (17) is given by:

$$
\mathrm{H}=\mathrm{u}(\mathrm{c}, \mathrm{r})+\mathrm{v}(\mathrm{k})-\mathrm{z}(\Phi)+\lambda_{\mathrm{k}}[\mathrm{k}(\mathrm{A}-\delta-\beta \mathrm{r}-\phi+\varphi \mathrm{k})-\mathrm{c}-\mathrm{r}]+\lambda_{\mathrm{r}} \Phi
$$

Thus, the first order conditions are:

$$
\begin{gathered}
\mathrm{u}_{\mathrm{c}}=\lambda_{\mathrm{k}} \\
\mathrm{z}_{\Phi}=\lambda_{\mathrm{r}} \\
\left(\dot{\lambda}_{\mathrm{k}}\right)=\rho \lambda_{\mathrm{k}}-\mathrm{V}_{\mathrm{k}}-\lambda_{\mathrm{k}}[\mathrm{A}-\beta \mathrm{r}-\phi+2 \varphi \mathrm{k}] \\
\dot{\lambda}_{r}=\rho \lambda_{r}-u_{r}+\lambda_{k}[\beta k+1]
\end{gathered}
$$

To simplify, we consider the utility function as being additively separable, and given by $\mathrm{u}(\mathrm{c}, \mathrm{r})=\zeta \mathrm{c}+\xi \mathrm{r}$, the function $\mathrm{v}(\mathrm{k})=\mathrm{v}_{0} \mathrm{k}$, and an adjustment that is costly and quadratic, in accordance the suggestion of Wirl (2000), expressed as $z(\Phi)=1 / 2 \gamma \Phi^{2}$.

The hypothesis of an additive utility function was used to simplify our analysis. This hypothesis means that substitutability among goods does not depend on the quantity of that good consumed by society, and that at least one of the intertemporal substitution elasticities is assumed to be constant. That leads to a rigorous restriction regarding the social planner's behavior. Nevertheless, the hypothesis is 
commonly used in the literature for simplification purposes, as in Long and Plosser (1983). In addition, conclusive evidence that annuls this hypothesis does not stand, as that additivity has been detected by Selvanathan (1987), Clements, Yang and Zheng (1997) and Fleissig and Whitney (2007).

Thus, by substituting 19 and 20 into 21 and 22, and by applying the specifications of the functions suggested here, the canonic equations are given by:

$$
\begin{gathered}
\dot{k}=\mathrm{k}(\mathrm{A}-\beta \mathrm{r}-\phi+\varphi \mathrm{k})-\mathrm{c}-\mathrm{r} \\
\dot{r}=\frac{\lambda_{r}}{r} \\
\dot{\lambda_{k}}=\rho \lambda_{k}-v_{0}-\lambda_{k}(A-\beta r-\phi+2 \varphi k) \\
\dot{\lambda_{r}}=\rho \lambda_{r}-\xi_{r}+\lambda_{k}[\beta k+1]
\end{gathered}
$$

Therefore, the steady-state solutions obtained from the transversality conditions, and from (23) to (26), are given by:

$$
\begin{gathered}
r^{*}=\frac{\left(\frac{\xi-\varsigma}{\varsigma \beta}\right)^{2}(-\varphi)+\left(\frac{\xi-\varsigma}{\varsigma \beta}\right)(A-\phi)-c}{\left(\frac{\xi-\varsigma}{\varsigma}+1\right)} \\
k^{*}=\left(\frac{\xi-\varsigma}{\varsigma \beta}\right) \\
\lambda_{\mathrm{r}}^{*}=0 \\
\lambda_{\mathrm{k}}^{*}=\varsigma
\end{gathered}
$$

Thus, in order to apply the Hopf Bifurcation Theorem, we must obtain the Jacobian of 23 through 26, whose evolution around the steady-state 27 through 30 is given by:

$$
J=\left[\begin{array}{cccc}
X & -\left(\beta k^{*}+1\right) & 0 & 0 \\
0 & 0 & 0 & 0 \\
-\left(\lambda_{k}^{*} \alpha(\varphi)\right) & \lambda_{k}^{*} \beta & \rho-X & 0 \\
\lambda_{k}^{*} \beta & 0 & \left(\beta k^{*}+1\right) & \rho
\end{array}\right]
$$


where $X=\left[2 \mathrm{k}^{*}-\beta \mathrm{r}^{*}+\mathrm{A}-\phi+2 \varphi \mathrm{k}^{*}\right]$

Also, according to Dockner and Feichtinger (1991), the eigen values of a Jacobian of type 31 are given by:

$$
{ }_{1}^{3} \theta_{2}^{4}=\rho / 2 \pm \sqrt{(\rho / 2)^{2}-Y / 2 \pm(1 / 2) \sqrt{\left.Y^{2}-4|J|\right)}}
$$

where $\mathrm{Y}$ is the sum of the determinants,

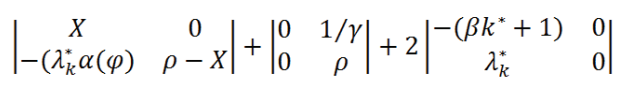

However, this Jacobian has a pair of eigen values that are purely imaginary if, and only if, the condition:

$$
\mathrm{Y}^{2}+2 \rho^{2} \mathrm{Y}=4|\mathrm{~J}|
$$

and

$$
\mathrm{Y}>0
$$

are met.

For our model, the Constant, $\mathrm{Y}$, and the determinant, $|\mathrm{J}|$, are given by:

$$
\begin{gathered}
\mathrm{Y}=\mathrm{X}(\rho-\mathrm{X}) \\
|\mathrm{J}|=1 / \gamma\left[(2 \mathrm{X}-\rho) \lambda_{\mathrm{k}}^{*} \beta\left(\beta \mathrm{k}^{*}+1\right)-\left(\beta \mathrm{k}^{*}+1\right)^{2}\left(2 \lambda_{\mathrm{k}}^{*}(\varphi)\right)\right]
\end{gathered}
$$

By applying the bifurcation conditions of (34) through (36) and (37), and by choosing as a bifurcation parameter, it is then possible to find the critical value $\gamma_{\text {crit }}$ givenby:

$$
\gamma_{\text {crit }}=\frac{\left[(2 X-\rho) \lambda_{k}^{*} \beta\left(\beta k^{*}+1\right)-\left(\beta k^{*}+1\right)^{2}\left(2 \lambda_{k}^{*}(\varphi)\right)\right]}{\frac{X(\rho-X)}{2}\left(\frac{X(\rho-X)}{2}+\rho^{2}\right)}
$$

Note that the steady-state values for $\left(k, r, \lambda_{k}, \lambda_{r}\right)$ do not depend on the parameter $\gamma$. Given these results, it is possible to formulate a proposition as follows:

a) proposition: considering the optimal control problem 17 and the equilibrium problem 27-30, Hopf's bifurcation, using $\gamma$ as a bifurcation parame- 
ter (whose criticalvalue is determined by (38), and assuming the validity of 34 and 35, leads to a limit in cycles;

b) proof: given the choice of the other parameters of the model, and considering the validity of conditions 34 and 35, the critical value may be calculated from 38. In such a case, the Jacobian arising around equilibrium assumes a purely imaginary pair of eigen values, with a non-null crossing velocity, such that it may be concluded that there are periodical solutions for both $\gamma>\gamma_{\text {crit }}$ and $\gamma<\gamma_{\text {crit }}$.

Our proposition establishes that the inclusion of regulatory policy adjustment costs in the AK growth model with environment, which was developed in section 2 , generates cyclical behavior involving a tension between the environment and the accumulation of capital stock. This theoretical formulation provides a plausible explanation for the stylized facts presented by Grossman and Krueger (1995, 1996).

Grossman and Krueger (1995, 1996) found a non-linear relationship similar to an inverted $U$ among such variables. In addition, Grossman and Krueger presented empirical evidence that the process would restart after reaching the end of the inverted U, with a new cycle beginning thereafter. The interpretation provided by the present model is that the inverted $U$ curve obtained by Grossman and Krueger is the first in a series of cycles over the long run, or multiple inverted U curves. The empirical evidence of the process restarting, as given by Grossman and Krueger, is consistent with this explanation.

The basic link between this result and the environmental Kuznets curve is the non linear relationship between pollution and economic growth. At the beginning of the development, regulatory institutions are not well established, and economic grow this therefore accompanied by increasing pollution. When the regulatory institutions receive the opportunity to tax pollution emissions, they do so more than proportionally because they know that there are costs to changing the regulatory tax. Thus, economic growth will be accompanied by a decrease in pollution.

We did not obtain any evidence for the cycles' stability. This is consistent with Wirl (1999), who demonstrated that the use of two state variables instead of one can increase complexity in the sense of optimum policies for environmental regulation leading to system instability. In other words, a rational strategy for an environmental policy does not necessarily imply stability (i.e., the sustainability of the environment).

Lastly, the theoretical suggestion offered by this model becomes relevant because it provides a formal answer to the statement that growth itself generates environmental protection mechanisms, thus justifying the need to protect the environment. We note that this model suggests the attention given to the environmental regulation problem ends up level ling off the environmental cycle, and that the environment is thus affected to a lesser degree. This result is fundamental since 
there is evidence that most natural resources are not renewable, making the role of environmental protection all the more crucial.

\section{Final Considerations}

After the empirical evidence produced by Grossman and Krueger (1995, 1996) showed that the relationship between per capita income and the concentrations of certain pollutants assumes an inverted-U shape, the economic literature has offered a vast array of theoretical alternatives for this fact, triggering an intense debate regarding environmental policies that might be adopted to address the issue.

Given this debate, our study sought to investigate the aforementioned relationship by suggesting a model for the environmental Kuznets curve. Our theoretical frame work is based on an expansion of the traditional AK growth model. Under our framework, the environmental Kuznets curve is obtained from a cyclical relation that exists between environmental regulation and the long-term accumulation of capital, which is due to the existence of regulatory policy adjustment costs and the statement of the hypothesis that there is a utility gain to capital stock formation vis-à-vis the environment.

In this context, we have sought to make the model more realistic by relaxing the hypothesis that variables like the accumulation of capital and institutional environmental protection regulations adjust instantaneously. The relaxation of this assumption abandons a theoretical simplification that was originally adopted to make the traditional model more analytically convenient and to offer a reasonable explanation for the environmental Kuznets curve.

Our analysis is divided into two parts. The first focuses on an extension of the traditional AK model with inclusion of the environment and a regulating agent. This is a simple introduction to the main model.

The second part of the analysis considers the inclusion of regulatory policy adjustment costs, and posits a cyclical relation between the environment and growth. The resulting system behaves similarly to the empirical findings observed for the environmental Kuznets curve.

The results obtained here not only provide an explanation for the empirical evidenceof a non-linear relationship between the environment and growth, but also show that this relationship may be the consequence of policies that reflect the complex choices associated with the adjustment costs of environmental regulation. In particular, our results suggest that the optimum policy strategy may be unstable, where environmental sustainability is not optimum. This further suggests that the evidence from the Kuznets environmental curve does not contradict this prediction. 
Thus, one of the conclusions of this study is the crucial emphasis on the fact that the environmental Kuznets curve, by itself, does not mean that economic growth leads automatically to environmental development. Rather, the environmental Kuznets curve is the result of a very long-term cyclical process between growth and the environment.

\section{References}

ANDREONI, J.; LEVINSON, A. The simple analytics of the environmental Kuznets curve. Journal of Public Economics, Amsterdam, v. 80, p. 269-286, 2001.

BELTRATTI, A. Sustainability of growth: reflections on economic models. Dordrecht: Kluwer Academic, 1996.

CHEVÉ, M. Irreversibility of pollution accumulation. Environmental and Resource Economics, Dordrecht, v. 16, n. 1, p. 93-104, 2000.

CLARK, C. W. Operational environmental policies. Environment and Development Economics, Cambridge, v. 1, n. 1, p. 110-113, 1996.

CLEMENTS, K.; YANG, W.; ZHENG, S. Is utility additive? The case of alcohol. Applied Economics, London, v. 29, n. 9, p. 1163-1167, 1997.

DOCKNER, E.; FEICHTINGER, G. On the optimality of limit cycles in dynamic economic systems. Journal of Economics, v. 53, n. 1, p. 31-50, 1991.

EL SERAFY, S.; GOODLAND, R. The importance of accurately measuring growth. Environment and Development Economics, Cambridge, v. 1, n. 1, p. 116-119, 1996.

FEICHTINGER, G.; NOVAK, A.; WIRL, F. Limit cycles in intertemporal adjustment models: theory and applications. Journal of Economic Dynamics and Control, Amsterdam, v. 18, n. 2, p. 353-380, 1994.

FLEISSIG, A.; WHITNEY, G. Testing additive separability. Economics Letters, Amsterdam, v. 96, n. 2, p. 215-220, 2007.

GROSSMAN, G.; KRUEGER, A. Economic growth and the environment. The Quarterly Journal of Economics, Cambridge, v. 110, n. 2, p. 353-377, 1995.

. The inverted-U: what does it mean. Environment and Development Economics, Cambridge, v. 1, n. 1, p. 119-122, 1996.

HAZILLA, M.; KOPP, R. J. Social cost of environmental quality regulations: a general equilibrium analysis. Journal of Political Economy, Chicago, v. 98, n. 4, p. 853-873, 1990.

JAEGER, W. Growth and environmental resources: a theoretical basis for the U-shaped environmental path. London: Williams College, 1998. 
JAFFE, A. B.; PETERSON, S. R.; PORTNEY, P. R.; STAVINS, R. N. Environmental regulation and the competitiveness of U.S. manufacturing: what does the evidence tell us? Journal of Economic Literature, Nashville, v. 33, n. 1, p. 132-163, 1995.

JOHN, A.; PECCHENINO, R. An overlapping generations model of growth and the environment. The Economic Journal, Oxford, v. 104, n. 427, p. 1393-1410, 1994.

JONES, L.; MANUELLI, R. E. Endogenous policy choice: the case of pollution and growth. Review of Economic Dynamics, Orlando, v. 4, n. 2, p. 369-405, 2001.

LEVINSON, A. The ups and downs of the environmental Kuznets curve. In: LIST, J.; ZEEUW, A. (Ed.). Recent advances in environmental economics. Cheltenham: Edgar Elgar, 2002.

LONG, J. B.; PLOSSER, C. Real business cycles. Journal of Political Economy, Chicago, v. 91, n. 1, p. 39-69, 1983.

MARGULIS, S. Back of the envelope estimates of environmental damage costs in Mexico. Washington: The World Bank, 1992. (Policy Research Working Papers, 824).

MICHEL, P.; ROTILLON, G. Disutility of pollution and endogenous growth. Environmental and Resource Economics, v. 6, n. 3, p. 279-300, 1995.

MOHTADI, H. Environment, growth, and optimal policy design. Journal of Public Economics, Amsterdam, v. 63, n. 1, p. 119-140, 1996.

PEARCE, D. W.; WARFORD, J. J. A world without end: economics, environment, and sustainable development. Oxford: Oxford University Press, 1993.

REIS, A. B. Endogenous growth and the possibility of eliminating pollution. Journal of Environmental Economics and Management, New York, v. 42, n. 3, p. 360-373, 2001.

RUBIO, S.J.; AZNAR, J. Sustainable growth and environmental policies. Milano: Fondazione Eni Enrico Mattei, 2000.

SCHMALENSEE, R. The costs of environmental protection. In: KOTOWSKI, M. (Ed.). Balancing economic growth and environmental goals: proceedings of a symposium sponsored by the American Council for Capital Formation. Washington: ACCF, 1993. p. 55-75.

SELDEN, T. M.; SONG, D. Neoclassical growth, the J curve forabatement, and the inverted U curve for pollution. Journal of Environmental Economics and Management, New York, v. 29, n. 2, p. 162-168, 1995.

SELVANATHAN, S. A Monte Carlo test of preference independence. Economics Letters, Amsterdam, v. 25, n. 3, p. 259-261, 1987.

SMULDERS, S. Economic growth, liberalization and the environment. In: CLEVELAND, C. (ed.). Encyclopedia of energy. Amsterdam: Elsevier, 2004.

SMULDERS, S.; GRADUS, R. Pollution abatement and long-term growth. European Journal of Political Economy, Amsterdam, v. 12, n. 3, p. 505-532, 1996. 
STOKEY, N. L. Are there limits to growth? International Economic Review, Philadelphia, v. 39, n. 1, p. 1-31, 1998.

WIRL, F. Complex dynamic environmental policies. Resource and Energy Economics, Amsterdam, v. 21, n. 1, p. 19-41, 1999.

. Optimal accumulation of pollution: existence of limit cycles for the social optimum and the competitive equilibrium. Journal of Economic Dynamics and Control, Amsterdam, v. 24, p. 297-306, 2000.

XEPAPADEAS, A. Economic development and environmental pollution: traps and growth. Structural Change and Economic Dynamics, Amsterdam, v. 8, n. 3, p. 327-350, 1997.

. Economic growth and the environment. In: MALER, K. G.; VINCENT, J. R. (Ed.). Handbook of environmental economics. Amsterdam: Elsevier, 2005. v. 3. cap. 23. p. 1219-1271.

\section{Appendix A - Phase diagram}

Figure 1: Phase Diagram

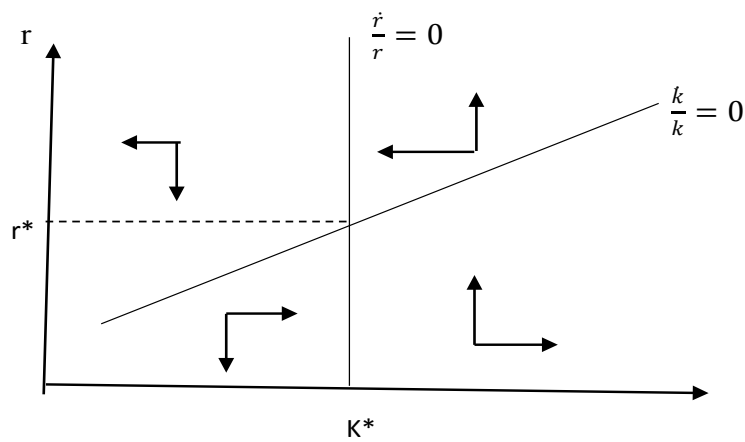

Source: Elaborated by authors.

Recebido em: 31/07/2014.

Aceito em: 05/09/2016. 